\title{
Waldenström Macroglobulinemia: A Clinicopathological Profile and Review of Six Cases
}

\begin{abstract}
Waldenström macroglobulinemia (WM) is an indolent B-cell neoplasm in which lymphoplasmacytic cells are accumulated in the bone marrow. This rare disease is incurable with the available treatments and its management is generally based on risk-adapted methods. We present here six cases of WM with their clinicopathological profile and response to therapy. This is a retrospective observational study conducted in a tertiary referral center in Eastern India from October 2014 to December 2016. The clinical manifestations, diagnostic challenges, and response to therapy for WM were analyzed. A total of six cases of WM were analyzed, of which five were male; the mean age was 65 years. The most common presentation was transfusion-dependent anemia, followed by hyperviscosity. All the patients had bone marrow infiltration by lymphoplasmacytoid cells, and serum protein electrophoresis and immunofixation showed immunoglobulin $\mathrm{M}$ kappa monoclonal protein. Bortezomib, dexamethasone, and rituximab (BDR) was the most commonly used regimen. Complete and very good partial responses were seen in one patient $(16.7 \%)$ each and partial response in $3(50 \%)$ patients. There was disease progression to diffuse large B-cell lymphoma in one patient $(16.7 \%)$. After a 26-month follow-up, four of six patients $(66.67 \%)$ remained free of disease progression. A very low incidence of WM was reported, and patients had a varied clinicopathological spectrum. A combination of BDR is a promising frontline therapy in the patients of WM.
\end{abstract}

Keywords: Bortezomib, BDR regimen, rituximab, Waldenström macroglobulinemia

\section{Introduction}

Waldenström macroglobulinemia (WM) is an indolent B-cell neoplasm, which is characterized by the accumulation of lymphoplasmacytic cells in bone marrow. It is a lymphoproliferative disorder in which a monoclonal immunoglobulin M (IgM) protein is produced. It is a rare disease with an incidence of $\sim 1 \%-2 \%$ of all hematologic cancers. $^{[1,2]}$

The clinical manifestations of WM include cytopenias, lymphadenopathy, hepatosplenomegaly, and neurologic symptoms and hyperviscosity. ${ }^{[3,4]}$ WM usually occurs in the elderly with a median age of 63 years at presentation. ${ }^{[1,2]}$ The disease has an overall survival of $5-10$ years. ${ }^{[3,4]}$ With the available treatments, WM is an incurable disease, and the patients are generally managed with risk-adapted methods. In this report, we present the clinicopathological

This is an open access journal, and articles are distributed under the terms of the Creative Commons Attribution-NonCommercial-ShareAlike 4.0 License, which allows others to remix, tweak, and build upon the work non-commercially, as long as appropriate credit is given and the new creations are licensed under the identical terms.

For reprints contact: WKHLRPMedknow_reprints@wolterskluwer.com profile and response to therapy in patients with WM.

\section{Methodology}

In this retrospective study, the records of patients were searched to detect cases of WM from a single tertiary care referral center in Eastern India. Six such cases were detected in 26 months, from October 2014 to December 2016, and their clinical manifestations, diagnostic challenges, response to treatment, and outcomes were analyzed. The Second International Workshop on WM (IWWM-2) proposed diagnostic criteria were used to establish the diagnosis, and further clinical, biochemical, hematological, and radiological investigations were analyzed. ${ }^{[5]}$ The International Prognostic Scoring System (IPSS) was used for risk stratification. The IWWM-6 criteria $^{[6]}$ was used for clinical response assessment, which was done after every two cycles with serum protein electrophoresis (SPEP) and by immunofixation after the disappearance of $\mathrm{M}$ band on SPEP.

How to cite this article: Samal $P$, Chakrabarti $P$ Waldenström macroglobulinemia: A Clinicopathological profile and review of six cases. Indian J Med Paediatr Oncol 2020;41:596-601.

\section{Priyanka Samal ${ }^{1}$ Prantar Chakrabarti ${ }^{2}$}

${ }^{1}$ Department of Clinical Hematology, Institute of Medical Sciences and SUM Hospital, Bhubaneswar, Odisha, India, ${ }^{2}$ Department of Clinical Hematology, Nilratan Sircar Medical College, Kolkata, West Bengal, India

Submitted: 16-Nov-2019

Revised: 13 -Dec-2019

Accepted: 31-Jan-2020

Published: 29-Aug-2020

Address for correspondence: Dr. Priyanka Samal, Department of Clinical Hematology, Institute of Medical Sciences and SUM Hospital, K8 Kalinga Nagar, Shampur, Bhubaneswar - 751 003, Odisha, India.

E-mail: samalpriyanka80@ gmail.com

Access this article online Website: www.ijmpo.org

DOI: 10.4103/ijmpo.ijmpo_234_19 Quick Response Code:

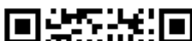

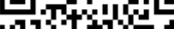
Ftrithis

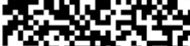

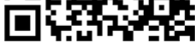




\section{Results}

\section{Clinicopathological profile}

There was a predominance of male gender $(5 / 83.3 \%)$, and four patients $(66.7 \%)$ were $\geq 65$ years of age, whereas the remaining two patients were $<65$ years. Transfusion-dependent anemia was the predominant presenting complaint, whereas two patients $(33.3 \%)$ had symptoms of hyperviscosity as the chief complaint [Table 1]. All the six patients had anemia, and none of them was positive for direct antiglobulin test. Two patients had leukopenia and thrombocytopenia in addition to anemia. Two patients had hepatomegaly, whereas none had lymphadenopathy.

Bone marrow aspirate and trephine biopsy demonstrated hypercellularity and infiltration by plasma cells, lymphocytes, and lymphoplasmacytoid cells. Dutcher bodies (periodic acid-Schiff +, intranuclear pseudoinclusions) were present within the lymphoplasmacytic cells. SPEP and immunofixation revealed IgM kappa in all the six cases. Quantitative IgM levels were elevated at diagnosis in all patients, and one patient with an IgM level of $113 \mathrm{~g} / \mathrm{L}$ had immune paresis. Serum $\beta_{2}$-microglobulin $>3 \mathrm{mg} / \mathrm{L}$ was seen in $4(66.7 \%)$ patients. None of these patients had evidence of hepatitis $\mathrm{C}$ virus infection. Four patients $(66.7 \%)$ were categorized as high risk based on IPSS WM scoring system, whereas one

\begin{tabular}{llc}
\hline \multicolumn{1}{c}{ Table 1: Clinicopathological profile of six cases } \\
\hline Clinicopathological & $\begin{array}{l}\text { Patient } \\
\text { characteristics }\end{array}$ & $\begin{array}{c}\text { Number of } \\
\text { patients, } \boldsymbol{n} \text { (\%) }\end{array}$ \\
\hline parameters & $<65$ & $2(33.3)$ \\
Age (years) & $\geq 65$ & $4(66.7)$ \\
Sex & Male & $5(83.3)$ \\
& Female & $1(16.7)$ \\
Hemoglobin $(\mathrm{g} / \mathrm{L})$ & $<115$ & $6(100)$ \\
& $\geq 115$ & 0 \\
Platelet count $\left(\times 10^{9} / \mathrm{L}\right)$ & $\leq 100$ & $2(33.3)$ \\
& $>100$ & $4(66.7)$ \\
Absolute neutrophil & $\leq 1.5$ & $2(33.3)$ \\
count $\left(\times 10^{9} / \mathrm{L}\right)$ & $>1.5$ & $4(66.7)$ \\
Organomegaly & Absent & $4(66.7)$ \\
& Present & $2(33.3)$ \\
Constitutional & Present & $6(100)$ \\
symptoms & Absent & 0 \\
Hyperviscosity & Present & $2(33.3)$ \\
symptoms & Absent & $4(66.7)$ \\
Serum monoclonal & $\leq 70$ & $4(66.7)$ \\
protein $(\mathrm{g} / \mathrm{L})$ & $>70$ & $2(33.3)$ \\
Serum albumin $(\mathrm{g} / \mathrm{L})$ & $\leq 35$ & $3(50)$ \\
Serum $\beta_{2}$-microglobulin & $\leq 3.0$ & $3(50)$ \\
(mg/L) & $>3.0$ & $2(33.3)$ \\
& Low risk & $4(66.7)$ \\
$(0$ or 1 except for age) & $1(16.7)$ \\
\hline & & \\
\hline & & \\
& &
\end{tabular}

patient each (16.7\%) fell in the intermediate- and low-risk groups [Table 1].

\section{Treatment and outcomes}

All the patients were symptomatic and required therapy. Patients received different combination therapies. Two patients $(33.3 \%)$ who presented with symptoms of hyperviscosity and high IgM levels underwent therapeutic plasma exchange along with cytoreductive chemotherapy, whereas the rest of the patients received only chemotherapy. "IgM flare" was seen in one patient $(16.7 \%)$ who responded to further cycles of plasmapheresis, and rechallenge with rituximab was tolerated well.

The most common regimen used was bortezomib, dexamethasone, and rituximab (BDR) for 6 cycles. Each 3-weekly treatment cycles consisted of:

- Bortezomib $1.3 \mathrm{mg} / \mathrm{m}^{2} \mathrm{IV}$ and dexamethasone $40 \mathrm{mg}$ IV on days $1,4,8$, and 11

- Rituximab $375 \mathrm{mg} / \mathrm{m}^{2} \mathrm{IV}$ on day 11.

Patients received four consecutive cycles as induction therapy, followed by four more cycles as a maintenance therapy at 3-monthly intervals. Two patients (33.3\%) also received bendamustine in addition to the above three drugs as in 4-weekly cycles:

- Bendamustine $90 \mathrm{mg} / \mathrm{m}^{2} \mathrm{IV}$ on days 1 and 2 and

- Rituximab $375 \mathrm{mg} / \mathrm{m}^{2} \mathrm{IV}$ on day 1

- Prophylactic granulocyte-colony-stimulating factor was also given.

All patients received antiviral prophylaxis for herpes zoster. Of the six patients, one patient (16.7\%) achieved a complete response (CR), one (16.7\%) had a very good partial response (VGPR), and three (50\%) had a partial response (PR). One patient (16.67\%) had disease progression with transformation to diffuse large B-cell lymphoma (DLBCL) [Table 2].

Bone marrow biopsy after therapy was done in the patient with $\mathrm{CR}$, which confirmed the $\mathrm{CR}$ with no evidence of disease. One patient who received eight cycles of BDR chemotherapy died due to sudden cardiac arrest with a PR of the disease at demise. The patient with the progression of disease to non-Hodgkin lymphoma DLBCL after five cycles of chemotherapy was treated with four cycles of rituximab, cyclophosphamide, vincristine, and prednisolone (R-CVP) as the patient was elderly and had cardiac comorbidities. Following the fourth cycle of R-CVP, the patient developed Fournier gangrene and died of septicemia. With a follow-up of 26 months, four of six patients $(66.7 \%)$ remained free of disease progression. The combined proportion of patients achieving CR, VGPR, and PR was seen in $83.3 \%$ of our patients.

One patient received methylprednisolone and rituximab as the first cycle due to high IPSS score and Eastern Cooperative Oncology Group performance of $>3$. However, his clinical condition improved, and subsequently, he 
Table 2: Overall response to different chemotherapy regimens

\begin{tabular}{|c|c|c|c|c|c|c|c|c|c|}
\hline $\begin{array}{l}\text { Age } \\
\text { (years) }\end{array}$ & Sex & $\begin{array}{l}\text { Presenting } \\
\text { symptom }\end{array}$ & $\begin{array}{c}\text { Serum } \\
\text { IgM level } \\
(\mathrm{g} / \mathrm{L})\end{array}$ & $\underset{(\mathrm{mg} / \mathrm{L})}{\beta_{2}-\text { microglobulin }}$ & $\begin{array}{l}\text { IPSS } \\
\text { score/risk group }\end{array}$ & Plasmapheresis & Chemotherapy & Response & $\begin{array}{l}\text { Current } \\
\text { status }\end{array}$ \\
\hline 56 & Male & Pancytopenia & 43.1 & 2.5 & 2 (intermediate) & No & BDR - 8 cycles & PR & $\begin{array}{l}\text { Died (sudden } \\
\text { cardiac arrest) }\end{array}$ \\
\hline 49 & Female & $\begin{array}{l}\text { Constitutional } \\
\text { symptoms }\end{array}$ & 45.1 & 2.3 & 1 (low) & No & BDR - 8 cycles & $\mathrm{CR}$ & Alive \\
\hline 80 & Male & $\begin{array}{l}\text { Transfusion } \\
\text {-dependent } \\
\text { anemia }\end{array}$ & 27.2 & 5.5 & 3 (high) & No & $\begin{array}{l}\text { Benda }+ \text { dexa }-1 \\
\text { cycle } \\
\text { BBD - } 2 \text { cycles } \\
\text { BBDR - } 3 \\
\text { cycles }\end{array}$ & PR & $\begin{array}{l}\text { Died } \\
\text { (postmeasles) }\end{array}$ \\
\hline 70 & Male & Hyperviscosity & 113 & 4.6 & 4 (high) & Yes & $\begin{array}{l}\text { Benda+dexa - } 1 \\
\text { cycle } \\
\text { BBDR - } 4 \\
\text { cycles } \\
\text { R-CVP - } 4 \\
\text { cycles }\end{array}$ & PD & Died (sepsis) \\
\hline 71 & Male & Hyperviscosity & 98 & 3.9 & 4 (high) & Yes & BDR - 8 cycles & VGPR & Alive \\
\hline 66 & Male & Pancytopenia & 25.3 & 4.3 & 4 (high) & No & $\begin{array}{l}\text { MPS+R - } 1 \\
\text { cycle }\end{array}$ & $\mathrm{PR}$ & Alive \\
\hline
\end{tabular}

BDR - Bortezomib, dexamethasone, rituximab; CR - Complete response; BBD - Bendamustine, bortezomib, dexamethasone; BBDR - BBD, rituximab; VGPR - Very good partial response; R-CVP - Rituximab, cyclophosphamide, vincristine, prednisolone; PR - Partial response; MPS+R - Methylprednisolone, rituximab; PD - Progressive disease; IgM - Immunoglobulin M; IPSS - International Prognostic Scoring System

received three more cycles of BDR. Patients' follow-up done in December 2019 revealed the current status of the patients as alive in three (one patient each had CR and PR and the third patient had relapsed disease after 7 months) and death in three patients (one due to sudden cardiac arrest with PR at demise, one due to sepsis who had progressive disease, and the third patient died post measles with PR at demise). The patient who had progressive disease after 7 months was further treated with six cycles of dexamethasone/rituximab/ cyclophosphamide (DRC) and reported VGPR.

Peripheral neuropathy was the most common toxicity. However, bortezomib was better tolerated with reduced toxicity on weekly subcutaneous administration. Bendamustine therapy was associated with episodes of febrile neutropenia.

\section{Discussion}

WM, also known as lymphoplasmacytic lymphoma (LPL), is a rare indolent non-Hodgkin lymphoma (incidence: $1 \%-2 \%$ of hematologic malignancies). It is characterized by excessive proliferation of lymphoplasmacytic cells in the bone marrow and is associated with the presence of serum monoclonal $\operatorname{IgM}$ antibody. ${ }^{[7]}$ We report here a retrospective analysis of six cases of WM and provide the details pertaining to the clinicopathological profile and response to therapy.

WM occurs mostly in elderly population, with a median age of diagnosis of $63-68$ years. ${ }^{[8]}$ The mean age of the patients was 65 years in our study, similar to the aforementioned evidence. A higher age-adjusted incidence rate of WM was reported in males as compared with females in the US and EU populations. ${ }^{[8]} \mathrm{A}$ similar trend of male preponderance was reported in our study too.

Anemia, fatigue, and weakness are the most common early symptoms of WM. ${ }^{[5]}$ Other common symptoms include decreased weight, fever, night sweats, lymphadenopathy, splenomegaly, hepatomegaly, peripheral neuropathy, hyperviscosity syndrome, and hemolytic anemia. ${ }^{[9,10]}$ All the patients $(100 \%)$ in our study had symptomatic anemia, whereas two of the six $(33.3 \%)$ had symptoms of hyperviscosity and $1(16 \%)$ patient had B symptoms. The high IgM serum levels $(>50 \mathrm{~g} / \mathrm{L})$ correspond to the increased risk of hyperviscosity syndrome, a very common clinical feature of WM. ${ }^{[1]}$ The two patients with hyperviscosity in our study had serum IgM levels of $>70 \mathrm{~g} / \mathrm{L}$.

According to the IWWM-2, the diagnosis of WM is exclusively based on the presence of LPL and an IgM monoclonal protein. The requirement for a threshold for marrow involvement by LPL or serum IgM concentration was removed for WM diagnosis. ${ }^{[12]}$ In the present study, all the six patients $(100 \%)$ had bone marrow involvement and had IgM monoclonal gammopathy. Approximately $10 \%-15 \%$ of $\mathrm{WM}$ patients transform into aggressive DLBCL type with extramedullary involvement. ${ }^{[13]}$ One of the six patients $(16.7 \%)$ in this study progressed to DLBCL. 
Therapy is not indicated in all the patients of WM; it is required only in patients with symptomatic disease. ${ }^{[4,14]}$ Alkylating agents and nucleoside analogs had been used for WM for several decades in the past $^{[4,10,15]}$ but are associated with only a transient response. Rituximab has a low toxicity profile and is currently used extensively for WM treatment. ${ }^{[10,16]}$ "IgM flare" (transient increase in serum IgM levels) is reported in a large population of patients (30\%-80\%) treated with rituximab. The IgM flare may cause a worsening of the disease and may lead to hyperviscosity syndrome. ${ }^{[4]}$ Hence, in majority of the regimens, rituximab is used after chemotherapy to avoid the IgM flare. A better treatment response with combination therapy (such as DRC regimen) with rituximab is reported as compared to rituximab monotherapy. However, it is associated with an infrequent response profile and a high time to response (median: 4 months). ${ }^{[17]}$ The more intensive chemotherapy regimens with rituximab (including rituximab, cyclophosphamide, doxorubicin, vincristine, and prednisone or nucleoside analogs [fludarabine/rituximab, fludarabine/cyclophosphamide/ rituximab, and rituximab/cladribine]) may yield a better response, but the associated morbidity and mortality are also increased. Furthermore, an increase in the cost of supportive therapy is also observed. ${ }^{[10,17]}$

The combination of rituximab with dexamethasone and bortezomib (the BDR regimen) is an active, chemotherapy-free regimen, which has reported a durable efficacy and long-term favorable toxicity profile for the treatment of WM in clinical studies. ${ }^{[18]}$ The BDR was the most commonly used regimen in our study. All the three patients treated with BDR regimen in our study had a response (CR/VGPR/
PR), which is comparable to the results reported in a previous long-term (6-year follow-up) Phase 2 study (response: $85 \%$ ). ${ }^{[18]}$ Overall, in our study, $83.3 \%$ of the patients had response. The median time to the first response was 4 months in our study, similar to earlier reports. ${ }^{[19,20]}$ Table 3 provides a comparison of previous studies with different regimens used for WM with the current study.

Two patients received bendamustine in combination with BDR regimen in our study. Previous studies have established the efficacy of bendamustine and rituximab combination for WM. The response rate with $\mathrm{DRC}, \mathrm{BDR}$, and rituximab-bendamustine was reported to be $76 \%, 85 \%$, and $96 \%$ for WM. ${ }^{[23]}$

As majority of the patients with WM are elderly in general, the therapy-related tolerability and toxicity profile should be considered carefully. The risk of myelotoxicity is limited with the use of $\mathrm{BDR}$ regimen as evidenced in previous clinical studies. ${ }^{[19,20]}$ Hence, this regimen can be used in patients presenting with cytopenia, as reported in our study. The twice-weekly administration of bortezomib-based regimen in our series was well tolerated, with peripheral neuropathy being the most common adverse event. However, none of the patients in our study on BDR discontinued therapy due to neuropathy. These results are similar to the previously published studies. ${ }^{[19,20]}$ Furthermore, most of our patients had reversible neuropathy. The use of bendamustine in WM has resulted in a good overall response rate; however, occasional myelosuppression is reported. ${ }^{[10]}$

Overall, DRC and BDR regimens are effective with an established satisfactory toxicity profile for the treatment

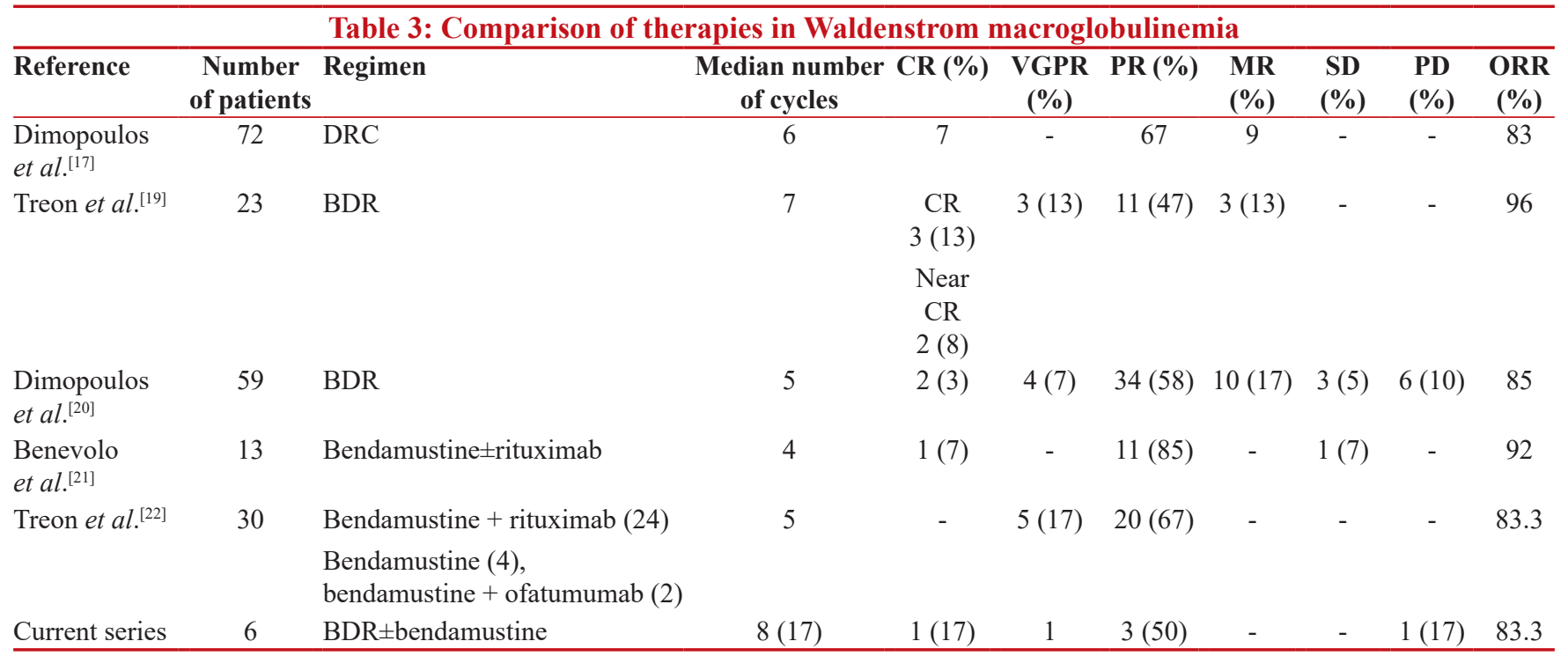

CR - Complete response; VGPR - Very good partial response; PR - Partial response; MR - Minimal response; SD - Stable disease; PD - Progressive disease; ORR - Overall response rate; DRC - Dexamethasone, rituximab, cyclophosphamide; BDR - Bortezomib, dexamethasone, rituximab 
of WM. The preferred regimen for WM depends on the patient characteristics. The DRC regimen can be preferred in patients with less pronounced cytopenias, low IgM levels, or poor regimen compliance, whereas BDR can be preferred in patients with high IgM levels and presenting symptoms of severe cytopenia or hyperviscosity.

\section{Conclusions}

WM is a rare disease, and there is no single established standard of care. Clinical presentation varies widely, and selection of chemotherapeutic protocols should aim at optimizing response, reducing toxicity, and leaving future treatment options open. Our experience in these six cases supports the use of BDR as the primary frontline therapy in most cases of WM, and clinical response and PFS rates correlate well with earlier cohort studies. However, multi-institutional prospective cohort studies of WM are required to get a clearer picture of the disease and its management in India, as majority of the patients here present to physicians at advanced stage when they become symptomatic.

\section{Acknowledgments}

We would like to thank Mr. Shreekant Sharma (ISMPP CMPP ${ }^{\mathrm{TM}}$, Lambda Therapeutic Research Ltd.) for medical writing assistance to our original manuscript and follow-up with the journal/publisher and Dr. Venugopal Madhusudhana (ISMPP CMPP $^{\mathrm{TM}}$, Lambda Therapeutic Research) for additional editorial assistance. The manuscript development support was provided by Intas Pharmaceuticals Ltd.

\section{Financial support and sponsorship}

Nil.

\section{Conflicts of interest}

There are no conflicts of interest.

\section{References}

1. Fonseca R, Witzig TE. Waldenström macroglobulinemia. In: Greer JP, Forester J, Lukens JN, Rodgers GM, Paraskevas F, Glader B, editors. Wintrobe's Clinical Hematology. Philadelphia: Lippincott Williams and Wilkins; 2004. p. 266774.

2. Herrinton LJ, Weiss NS. Incidence of Waldenstrom's macroglobulinemia. Blood 1993;82:3148-50.

3. Dimopoulos MA, Galani E, Matsouka C. Waldenström's macroglobulinemia. Hematol Oncol Clin North Am 1999;13:1351-66.

4. Treon SP. How I treat Waldenström macroglobulinemia. Blood 2015;126:721-32.

5. Owen RG, Treon SP, Al-Katib A, Fonseca R, Greipp PR, McMaster ML, et al. Clinicopathological definition of Waldenstrom's macroglobulinemia: Consensus panel recommendations from the Second International Workshop on Waldenstrom's Macroglobulinemia. Semin Oncol 2003;30:110-5.
6. Owen RG, Kyle RA, Stone MJ, Rawstron AC, Leblond V, Merlini G, et al. Response assessment in Waldenström macroglobulinaemia: Update from the VIth International Workshop. Br J Haematol 2013;160:171-6.

7. Vijay A, Gertz MA. Waldenström macroglobulinemia. Blood 2007;109:5096-103.

8. Buske C, Leblond V. How to manage Waldenstrom's macroglobulinemia. Leukemia 2013;27:762-72.

9. Björkholm M, Johansson E, Papamichael D, Celsing F, Matthews J, Lister TA, et al. Patterns of clinical presentation, treatment, and outcome in patients with Waldenstrom's macroglobulinemia: A two-institution study. Semin Oncol 2003;30:226-30.

10. Oza A, Rajkumar SV. Waldenstrom macroglobulinemia: Prognosis and management. Blood Cancer J 2015;5:e394.

11. Gustine JN, Meid K, Dubeau T, Hunter ZR, Xu L, Yang G, et al. Serum IgM level as predictor of symptomatic hyperviscosity in patients with Waldenström macroglobulinaemia. Br J Haematol 2017;177:717-25.

12. Ansell SM, Kyle RA, Reeder CB, Fonseca R, Mikhael JR, Morice WG, et al. Diagnosis and management of Waldenström macroglobulinemia: Mayo stratification of macroglobulinemia and risk-adapted therapy (mSMART) guidelines. Mayo Clin Proc 2010;85:824-33.

13. Lin P, Mansoor A, Bueso-Ramos C, Hao S, Lai R, Medeiros LJ. Diffuse large B-cell lymphoma occurring in patients with lymphoplasmacytic lymphoma/Waldenström macroglobulinemia. Clinicopathologic features of 12 cases. Am J Clin Pathol 2003;120:246-53.

14. Gertz MA. Waldenström macroglobulinemia: 2012 update on diagnosis, risk stratification, and management. Am J Hematol 2012;87:503-10.

15. Dimopoulos MA, Weber DM, Kantarjian H, Keating M, Alexanian R. 2Chlorodeoxyadenosine therapy of patients with Waldenstrom macroglobulinemia previously treated with fludarabine. Ann Oncol 1994;5:288-9.

16. Weide R, Heymanns J, Köppler H. Induction of complete haematological remission after monotherapy with anti-CD20 monoclonal antibody (RITUXIMAB) in a patient with alkylating agent resistant Waldenström's macroglobulinaemia. Leuk Lymphoma 1999;36:203-6.

17. Dimopoulos MA, Anagnostopoulos A, Kyrtsonis MC, Zervas K, Tsatalas C, Kokkinis G, et al. Primary treatment of Waldenström macroglobulinemia with dexamethasone, rituximab, and cyclophosphamide. J Clin Oncol 2007;25:3344-9.

18. Gavriatopoulou M, García-Sanz R, Kastritis E, Morel P, Kyrtsonis MC, Michalis E, et al. BDR in newly diagnosed patients with WM: Final analysis of a phase 2 study after a minimum follow-up of 6 years. Blood 2017;129:456-9.

19. Treon SP, Ioakimidis L, Soumerai JD, Patterson CJ, Sheehy P, Nelson M, et al. Primary therapy of Waldenström macroglobulinemia with bortezomib, dexamethasone, and rituximab: WMCTG clinical trial 05-180. J Clin Oncol 2009;27:3830-5.

20. Dimopoulos MA, García-Sanz R, Gavriatopoulou M, Morel P, Kyrtsonis MC, Michalis E, et al. Primary therapy of Waldenstrom macroglobulinemia (WM) with weekly bortezomib, low-dose dexamethasone, and rituximab (BDR): Long-term results of a phase 2 study of the European Myeloma Network (EMN). Blood 2013; 122:3276-82.

21. Benevolo G, LobettiBodoni C, Orsucci L, Botto B, Chiappella A, Riccomagno P, et al. In: Safety and Efficacy of Bendamustine 
Therapy in Waldenström Macroglobulinemia. Amsterdam: Poster Session Presented at the $17^{\text {th }}$ Congress of European Hematology Association; 2012.

22. Treon SP, Hanzis C, Tripsas C, Ioakimidis L, Patterson CJ, Manning RJ, et al. Bendamustine therapy in patients with relapsed or refractory Waldenström's macroglobulinemia. Clin Lymphoma Myeloma Leuk 2011;11:133-5.
23. Abeykoon JP, Zanwar S, Ansell SM, Kumar S, Thompson CA, Habermann TM, et al. Outcomes with rituximab plus bendamustine (R-Benda), dexamethasone, rituximab, cyclophosphamide (DRC), and bortezomib, dexamethasone, rituximab (BDR) as primary therapy in patients with Waldenstrom macroglobulinemia (WM). J Clin Oncol 2019;37 Suppl 15:7509. 